\title{
Etiopathogenesis of inflammatory pseudotumors of the liver
}

\author{
Nicolae BACALBASA ${ }^{1,2,3}$, Irina BALESCU ${ }^{4}$, Camelia C. DIACONU ${ }^{1,5}$, Laura ILIESCU ${ }^{1,6}$, \\ Mihaela VILCU ${ }^{1,7}$, Lucian POP ${ }^{8}$, Mihai DIMITRIU ${ }^{1,9}$, Cristian BALALAU ${ }^{1,10}$, \\ Alexandru FILIPESCU ${ }^{1,11}$, Carmen SAVU ${ }^{12}$, Cornel SAVU ${ }^{1,13}$, Emil BELU ${ }^{14}$, Iulian BREZEAN ${ }^{1,7}$ \\ 1"Carol Davila" University of Medicine and Pharmacy, Bucharest, Romania \\ ${ }^{2}$ Department of Obstetrics and Gynecology, \\ “I. Cantacuzino" Clinical Hospital, Bucharest, Romania \\ ${ }^{3}$ Department of Visceral Surgery, Center of Excellence in Translational Medicine \\ Fundeni Clinical Institute, Bucharest, Romania \\ ${ }^{4}$ Department of Surgery, Ponderas Academic Hospital, Bucharest, Romania \\ ${ }^{5}$ Department of Internal Medicine, University Emergency Hospital Bucharest, Bucharest, Romania \\ ${ }^{6}$ Department of Internal Medicine, Fundeni Clinical Institute, Bucharest, Romania \\ 7Department of Surgery, "I. Cantacuzino" Clinical Hospital, Bucharest, Romania \\ 8"Alessandrescu-Rusescu" National Institute of Mother and Child Health, \\ Fetal Medicine Excellence Research Center, Bucharest, Romania \\ ${ }^{9}$ Department of Obstetrics and Gynecology, \\ "Sf. Pantelimon" Emergency Clinical Hospital, Bucharest, Romania \\ ${ }^{10}$ Department of Surgery, Pantelimon Clinical Hospital, Bucharest, Romania \\ ${ }^{11}$ Department of Obstetrics and Gynecology, Elias Emergency Hospital, Bucharest, Romania \\ ${ }^{12}$ Department of Anesthesiology, Fundeni Clinical Institute, Bucharest, Romania \\ ${ }^{13}$ Department of Thoracic Surgery, "Marius Nasta" Institute of Pneumonology, Bucharest, Romania \\ ${ }^{14}$ Department of Oncology, "Prof. Dr. Al. Trestioreanu" Institute of Oncology Bucharest Romania
}

\section{ABSTRACT}

Inflammatory pseudotumors of the liver are rare entities, only few cases being reported so far, pathogenesis of these lesions being scarcely understood. However since now multiple mechanisms have been proposed in order to explain the development of these lesions, the knowledge of their pathogenesis being mandatory in order to further orientate the therapeutic strategy. The current paper is a literature review of the largest studies which aimed to discuss the etiopathogenesis of the inflammatory pseudotumors of the liver.

Keywords: inflammatory pseudotumors, etiopathogenesis, liver

\footnotetext{
Abbreviations

$\mathrm{IPL}=$ Inflammatory pseudotumors of the liver

IgG4 = Immunoglobulin G4

CD34 = Cluster of differentiation 34
} 


\section{INTRODUCTION}

Inflammatory pseudotumors of the liver (IPL) have been rarely reported so far, less than 300 cases being described until present (1). Therefore, experience in terms of diagnostic of such lesions remains poor, a significant number of cases being initially misdiagnosed and considered as malignant lesions (2-7). In this respect, it can be understood why the mechanism of their development is still poorly understood.

\section{COMMON THEORIES EXPLAINING THE PATHOGENESIS OF IPL}

The pathogenesis of inflammatory pseudotumors of the liver (IPL) (also known as inflammatory myofibroblastic tumors) is not well understood at this moment, many theories being proposed so far. The most commonly incriminated ones are related to immune and even auto-immune reaction, intraparenchymal hemorrhage, necrosis, infection, occlusive phlebitis, chronic cholangitis or as a result of intrahepatic rupture of a biliary branch $(2,3,8)$; other authors consider that IPL are caused by the exposure of the bile ducts to noxious, toxic agents (9).

\section{THE INFECTIOUS THEORY}

Perhaps the most widely accepted theory so far is the infectious one; according to this theory, microorganisms from food or certain abdominal conditions such as chronic appendicitis or diverticular sigmoiditis seed the liver parenchyma through the portal vein flow; in this context obliterating phlebitis, chronic inflammation and granulomatous degeneration will develop at the level of the liver parenchyma (4). The most commonly incriminated bacterial agents are represented by Escherichia coli, Gram positive cocci, Staphylococcus aureus and even Mycobacterium tuberculosis (10-12). This theory is best described by Horiuchi's study which was conducted on nine cases of patients diagnosed with IPL and published in 1990 (4). The authors underline the fact that from the histopathological point of view, IPL are in fact hepatic abscesses presenting areas of granulomatous degeneration characterized by the presence of giant cells and histiocytes $(4,13)$. Moreover, other authors proposed a direct correlation between Epstein-Barr virus and IPL development due to the presence of inflammatory follicular dendritic cell tumors (14); however, the hypothesis remains a doubtful one $(10,15)$.

\section{THE IMMUNOLOGICAL THEORY}

The presence of a high amount of plasma cells at the level of IPL enabled certain authors to consider that these hepatic lesions have an immunological trigger (16). Therefore, association between IPL and other autoimmune entities such as Crohn's disease, Sjögren's syndrome, Kostmann's disease, primary sclerosing cholangitis and autoimmune pancreatitis has been reported so far inducing the idea of a possible common pathogenesis of these entities (4-6); in such cases is believed that an immune reaction and even an autoimmune phenomena might represent the trigger for the development of both pathogenic conditions $(6,7,17-20)$. The correlation between primary sclerosing cholangitis and IPL seems to be a more complex one; therefore, it has been stated that the trigger is represented by the presence of increased amounts of monomeric bile acids in the absence of biliary phospholipid secretion. This condition seems to be responsible for the apparition of bile duct injuries as well as for the process of pericholangitis, fibrosis and finally for the development of chronic sclerosing cholangitis (21). In the meantime, the injury of the biliary epithelial cells will allow the extravasation of toxic bile as well as the accumulation of these products in the subepithelial tissue; this is the trigger for the local invasion of neutrophil granulocytes which induce chronic inflammation, ulceration, activation of periductal myofibroblasts and development of pericanalicular fibrosis (21). Moreover, the theory of the immunological trigger is also sustained by the studies which underline the association between immunoglobulin G4 (IgG4) related sclerosing disease and the apparition of IPL; defined by the presence of IgG4 positive plasma cells and $T$ cells in different tissues, this condition is correlated with the development of autoimmune diseases such as chronic pancreatitis, sclerosing cholangitis, retroperitoneal fibrosis, interstitial pneumonia and even IPL $(22,23)$. Moreover, gallstones development might induce a chronic inflammatory response which will further create the premises of IPL development (24).

The theory of chronic cholangitis was also demonstrated by Terada et al. in 1992; in this paper the authors presented the case of a 67 year old patient presenting a tumor like lesion of $1.2 \mathrm{~cm}$ in the left lobe in association with chronic dilatation of the common and hepatic bile ducts; the tumor was enucleated while the histopathological studies demonstrated the presence of areas of dilated bile ducts in association with periductal fibrosis, hyalinization of the connective tissue and lymphocytic and plasmacytic infiltrates, inducing in this way the idea of the presence of a IPL (8).

\section{THE VASCULAR THEORY}

Another suspected theory is the vascular one, the IPL being the result of intraparenchimatous hemorrhage caused by coagulopathy or surgical trauma (25). 
Once IPL develop, microvascular involvement of the surrounding structures will appear and occlusive phlebitis will develop; in rare cases major vessels involvement might occur (4,26-28).

\section{THE HORMONAL THEORY}

A less frequently cited theory is hormonal one, certain authors demonstrating the presence of estrogen receptors at the level of the spindle cells in IPL, especially in cases diagnosed with inflammatory pseudotumor-like follicular dendritic cell tumors; moreover, this histopathological subtype of IPL is significantly more commonly encountered in women, demonstrating once again the possible influence of the hormonal balance. This aspect should be carefully analyzed, the presence of hormonal receptors at the level of such tumors making the patient a possible candidate for hormonal therapy $(14,29)$.

\section{THE GENETIC THEORY}

Meanwhile, certain studies proposed a genetic basis for the development of such lesions, chromosomal rearrangements of the anaplastic lymphoma kinase gene locus being incriminated in up to $65 \%$ of patients diagnosed with IPL (30). Moreover, the presence of this mutation seems to be associated with the risk of local recurrence while it's absence is associated with higher survival rates transforming in this way the genetic factor into an important prognostic factor for the long term outcomes (30-32).

Due to the presence of high amount of inflammatory structures in these lesions a positive diagnostic might be hard to be established even after performing fine needle aspiration cytology or core biopsy; therefore, in a significant number of cases only a large amount of non-specific inflammatory cells will be revealed $(3,33)$. Histologically, IPL present densely hyalinized collagenous tissue which is widely infiltrated by plasma cells, spindle cells, lymphocytes and histiocytes (34). Meanwhile, immunohistochemical studies usually identify positive staining for smooth muscle actin and vimentin while desmin, S100 protein and cluster of differentiation 34 (CD34) are negative $(35,36)$.

\section{CONCLUSIONS}

IPL are rare hepatic lesions rarely reported so far meanwhile the mechanisms of development remains poor, multiple theories being proposed. Among these theories the most widely accepted ones are represented by the infectious and immunological theories. However, once the modalities of diagnostic will improve, larger studies are expected in order to provide a better understanding of the pathogenic mechanisms leading to the development of such cases.

\section{Acknowledgement}

This work was supported by the project entitled „Multidisciplinary Consortium for Supporting the Research Skills in Diagnosing, Treating and Identifying Predictive Factors of Malignant Gynecologic Disorders", project number PN-III-P1-1.2-PCCDI2017-0833.

Conflict of interest: none declared

\section{REFERENCES}

1. Yang TL, Chang HC. Inflammatory Pseudotumor of the Liver. Journal of Cancer Research and Practice. 2019:96-99.

2. Standiford SB, Sobel H, Dasmahapatra KS. Inflammatory pseudotumor of the liver. J Surg Oncol. 1989;40:283-287.

3. Locke JE, Choti MA, Torbenson MS et al. Inflammatory pseudotumor of the liver. $J$ Hepatobiliary Pancreat Surg. 2005;12:314-316.

4. Horiuchi R, Uchida T, Kojima T, Shikata T. Inflammatory pseudotumor of the liver. Clinicopathologic study and review of the literature. Cancer 1990;65:1583-1590.

5. Amankonah TD, Strom CB, Vierling JM, Petrovic LM. Inflammatory pseudotumor of the liver as the first manifestation of Crohn's disease. Am J Gastroenterol. 2001;96:2520-22.
6. Sasahira N, Kawabe T, Nakamura A et al. Inflammatory pseudotumor of the liver and peripheral eosinophilia in autoimmune pancreatitis. World J Gastroenterol. 2005;11:922-925.

7. Hertzer NR, Hawk WA, Hermann RE. Inflammatory lesions of the liver which simulate tumor: Report of two cases in children. Surgery 1971;69:839-846.

8. Terada T, Nakanuma Y, Nonomura A. Hamartomatous lesion of the liver in an adult patient with biliary dilatations: $A$ variant of inflammatory pseudotumor of the liver? Gastroenterol Jpn. 1992;27:258-263.

9. Tanino M, Ohta G. An autopsy case of xanthogranuloma in the liver (author's transl.). Nihon Shokakibyo Gakkai Zasshi 1981;78:1803-1806.

10. Tang L, Lai EC, Cong W M et al. Inflammatory myofibroblastic tumor of the liver: A cohort study. World J Surg. 2010;34:309-313.

11. Kasana V, Rajesh S, Chauhan U et al. Inflammatory Myofibroblastic Tumor of Liver Masquerading as Focal Nodular Hyperplasia in a Patient with Non-Cirrhotic Portal Hypertension and Biliary Pancreatitis. Indian J Surg Oncol. 2016;7:110-114.

12. Manolaki N, Vaos $\mathrm{G}$, Zavras $\mathrm{N}$ et al. Inflammatory myofibroblastic tumor of the liver due to Mycobacterium tuberculosis in an immunocompetent girl. Pediatr Surg Int. 2009;25:451-454

13. Noguchi T, Ogura Y, Mizumoto R. Granulomatous abscess of the liver. Liver Biliary System, Pancreas (in Japanese).1986;13:207-212.

14. Liu Y, Li L, Hu Q, Miranda RN. Inflammatory pseudotumor-like follicular dendritic cell 
tumor of the liver with expression of estrogen receptor suggests a pathogenic mechanism: A case report and review of the literature. Hematopathol. 2010;3:109-115.

15. Cheuk W, Chan JK, Shek TW et al. Inflammatory pseudotumor-like follicular dendritic cell tumor: A distinctive low-grade malignant intra-abdominal neoplasm with consistent Epstein-Barr virus association. Am J Surg Pathol. 2001;25:721-731.

16. Grouls V. Pseudolymphoma (inflammatory pseudotumor) of the liver. Zentralbl Allg Pathol. 1987; 133:565-568.

17. Someren A. "Inflammatory pseudotumor" of liver with occlusive phlebitis: Report of a case in a child and review of the literature. Am J Clin Pathol. 1978;69:176-181.

18. Hosokawa A, Takahashi H, Akaike J et al. A case of Sjögren's syndrome associated with inflammatory pseudotumor of the liver. Nihon Rinsho Meneki. Gakkai Kaishi 1998;21:226-233

19. Toda K, Yasuda I, Nishigaki $Y$ et al. Inflammatory pseudotumor of the liver with primary sclerosing cholangitis. J Gastroenterol. 2000;35:304-309.

20. Hsiao CC, Chen CL, Eng HL. Inflammatory pseudotumor of the liver in Kostmann's disease. Pediatr Surg Int. 1999;15:266-269.

21. Faraj W, Ajouz H, Mukherji D et al. Inflammatory pseudo-tumor of the liver: A rare pathological entity. World J Surg Oncol. 2011;9:5.

22. Kamisawa T, Takuma $\mathrm{K}$, Egawa $\mathrm{N}$ et al. Autoimmune pancreatitis and IgG4-related sclerosing disease. Nat Rev Gastroenterol Hepatol. 2010;7:401-409.

23. Notohara K, Arimoto M, Wani Y, Fujisawa M. Autoimmune pancreatitis: Pancreatic manifestation of IgG4-related disease. Pathol Case Rev. 2010;15:219-224.

24. Pantiora EV, Sakellaridis EP, Kontis EA, Fragulidis GP. Inflammatory Pseudotumor of the Liver Presented in a Patient with Cholelithiasis. Cureus. 2018;10:e3231.

25. Cotelingam JD, Jaffe ES. Inflammatory pseudotumor of the spleen. Am J Surg Pathol. 1984:8:375-380.

26. Anthony P P, Telesinghe P U. Inflammatory pseudotumour of the liver. J Clin Pathol. 1986;39:761-768.

27. Chen KT. Inflammatory pseudotumor of the liver. Hum.Pathol. 1984;15:694-696.

28. Kai K, Matsuyama S, Ohtsuka T et al. Multiple inflammatory pseudotumor of the liver, mimicking cholangiocarcinoma with tumor embolus in the hepatic vein: Report of a case. Surg Today. 2007;37:530-533.

29. Santos GA, Cunha IW, Rocha RM et al. Evaluation of estrogen receptor alpha, estrogen receptor beta, progesterone receptor, and cKIT expression in desmoids tumors and their role in determining treatment options. Biosci Trends. 2010;4:25-30.

30. Alaggio R, Cecchetto G, Bisogno G et al. Inflammatory myofibroblastic tumors in childhood: A report from the Italian Cooperative Group studies. Cancer. 2010;116:216-226.
31. Coffin CM, Hornick JL, Fletcher CD. Inflammatory myofibroblastic tumor: Comparison of clinicopathologic, histologic, and immunohistochemical features including ALK expression in atypical and aggressive cases. Am J Surg Pathol. 2007;31:509-520.

32. Guzman JPS and Caballes AB. Inflammatory Myofibroblastic Tumor of the Liver in Children. Journal of Pediatric Surgery Case Reports. 2020;52:101331.

33. Koea JB, Broadhurst GW, Rodgers MS, McCall JL. Inflammatory pseudotumor of the liver: Demographics, diagnosis, and the case for nonoperative management. J Am Coll Surg. 2003;196:226-235.

34. Shek TW, Ng IO, Chan KW. Inflammatory pseudotumor of the liver. Report of four cases and review of the literature. Am J Surg Pathol. 1993;17:231-238.

35. Palmer RH, Glickman PB, Kappas A. Pyrogenic and inflammatory properties of certain bile acids in man. $J$ Clin Invest. 1962;41:1573-1577.

36. Sari A, Tunakan M, Unsal B et al. Inflammatory pseudotumor of the liver diagnosed by needle biopsy: report of three cases (one with neuroendocrine tumor of the rectum and lung). Turk J Gastroenterol. 2010;21:308-312. 